\title{
Social support and protection from depression: systematic review of current findings in Western countries
}

Geneviève Gariépy, Helena Honkaniemi and Amélie Quesnel-Vallée

\section{Background}

Numerous studies report an association between social support and protection from depression, but no systematic review or meta-analysis exists on this topic.

\section{Aims}

To review systematically the characteristics of social support (types and source) associated with protection from depression across life periods (childhood and adolescence; adulthood; older age) and by study design (cross-sectional $v$. cohort studies).

\section{Method}

A systematic literature search conducted in February 2015 yielded 100 eligible studies. Study quality was assessed using a critical appraisal checklist, followed by meta-analyses.

\section{Results}

Sources of support varied across life periods, with parental support being most important among children and adolescents, whereas adults and older adults relied more on spouses, followed by family and then friends. Significant heterogeneity in social support measurement was noted. Effects were weaker in both magnitude and significance in cohort studies.

\section{Conclusions}

Knowledge gaps remain due to social support measurement heterogeneity and to evidence of reverse causality bias.

\section{Declaration of interest}

None.

\section{Copyright and usage}

(c) The Royal College of Psychiatrists 2016.
Depression is a prevalent mental condition across the globe and a main contributor to the global burden of disease. ${ }^{1}$ Although the risk factors for depression are well described, less is known about factors that enable individuals to bounce back from depression or even to avoid it altogether. ${ }^{2}$ Social support is hypothesised to protect mental health both directly through the benefits of social relationships and indirectly as a buffer against stressful circumstances. Social support is a multidimensional concept which broadly refers to the emotional (e.g. providing encouragement), instrumental (e.g. helping with housekeeping) or informational (e.g. notifying someone of a job opportunity) assistance that is received from others. ${ }^{3}$ It may also be characterised by the provider of support, including support from a spouse, relatives or friends, each thought to have independent protective effects against depression. Several reviewers have discussed aspects of social factors and mood problems in adult and elderly populations. ${ }^{4-8}$ Previous reviews have been mostly narrative, however, and none focused specifically on depression. In spite of the wealth of literature on social support, several questions remain. It is not clear which sources or types of social support are most protective against depression, or whether the type and source of support that is optimal for mental health varies across the life course. For example, parental support may be more important during childhood than adulthood. Answers to these questions may be useful for both policy-makers and clinicians in crafting targeted messages and interventions on social support, and to orient future research in this area. The aim of this paper was therefore to conduct a systematic literature review to summarise existing knowledge on social support and protection from depression. We explored evidence for different types of social support and summarised findings according to broad life periods (childhood and adolescence, adulthood, older adulthood).

\section{Method}

We conducted a systematic search in February 2015 to identify relevant studies in the following databases: PubMed Medline, ISI Web of Science and PsycINFO. No limits were set on publication dates. Database-specific electronic search terms were developed in consultation with a librarian and included the following terms and their variants: social support, social network, social capital, social isolation, social contacts, social integration; depression, depressive symptoms. The PubMed search strategy (including MeSH terms) is given as an example in online supplement DS1. We further searched reference lists of primary studies and review articles to identify any additional eligible studies.

\section{Study selection}

We considered eligible any observational study from the general population, across any life period, that assessed the association between social support (independent variable) and depression or depressive symptoms (dependent variable). Papers were included if they were original publications based on individual-level data and provided a quantitative measure of association (risk ratio, odds ratio, etc.). We reported estimates from the fully adjusted model wherever available. Since we were interested in the inverse relationship between social support and depression in the general population, we excluded studies on specific subpopulations. Furthermore, since this association is likely to be culturedependent, ${ }^{9}$ we also limited this review to Western countries, including the USA, Canada and Europe (EU and member states of the European Free Trade Association), Australia and New Zealand. We reviewed only publications that were in English, 
French or Finnish. Titles and abstracts were screened independently by two investigators (G.G. and H.H.) and disagreements were resolved by consensus or a third reviewer (A.Q.-V.). Interrater agreement was calculated using the agreement rate, simple kappa score and kappa score adjusted for prevalence and bias. We reported the last because the simple kappa score is sensitive to the proportion of studies eligible, which was low in this review $(0.6 \%) .{ }^{10}$

\section{Data extraction and quality assessment}

Data extraction and quality assessment of eligible studies were performed independently by two investigators (G.G. and H.H.). For each study we extracted study information, instruments used to assess social support and depression, and association estimates. The authors were contacted for additional information when necessary. We conducted a quality assessment of the studies using a modified version of the Newcastle-Ottawa Scale. ${ }^{11}$ The modified scale includes nine items about comparability, selection bias, information bias and control of at least three important confounders (see online supplement DS2 for items and rating criteria). Disagreements were resolved by discussion or by a third party (A.Q.-V.). We analysed studies by life periods (children and adolescents, adults and older adults) and study design (cross-sectional, cohort or case-control). Adult studies included samples restricted to adults and those from the general population mainly composed of adults.

\section{Statistical analysis}

We used meta-analytic methods to provide a general quantitative synthesis of the literature. Pooled results should be interpreted with caution because of the known high level of heterogeneity between studies. We included studies for which standard errors could be extracted or calculated (62 studies). We conducted separate analyses for dichotomous and continuous depression outcomes since they provide different effect estimates. We used odds ratios for dichotomous outcomes and standardised beta coefficients for continuous outcomes. We pooled estimates using the DerSimonian \& Laird random effects model. For studies that presented associations across categorical levels of social support (rather than linear scales) we included estimates comparing the highest and lowest level of support. For studies that provided results categorised by subgroups (e.g. gender) we combined results using a fixed effects model and included the pooled result in the analysis. We reverse-coded associations between absence of (or negative) social support, such that all estimates described the associations between presence of (or positive) social support and depressive symptoms or depression. High heterogeneity between studies was expected and evaluated descriptively by life period, broad categories of social support (general support; support from partner, from family, from friends and from work or school; emotional, instrumental and informational support) and type of study design. Publication bias was not assessed using quantitative methods because these are not recommended under conditions of high heterogeneity. ${ }^{12}$ Analyses were conducted in Stata version 12.1 .

\section{Results}

The final selection comprised 99 articles, of which one presented results from two studies, resulting in a total of 100 studies (Fig. 1). ${ }^{12-111}$ About two-thirds of studies were cross-sectional, a third longitudinal and none case-control (Table 1). These studies represent data from 504966 individuals (sample sizes ranged from 83 to 95103 ) and covered 27 years of published research

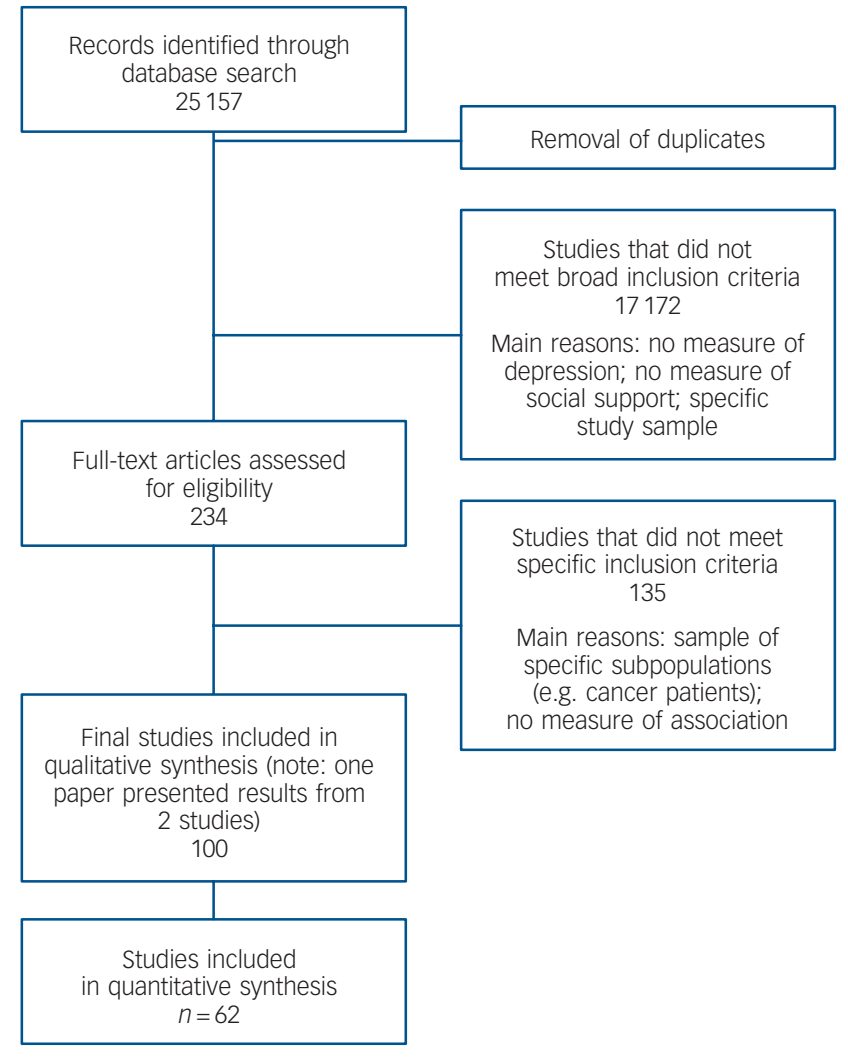

Fig. 1 Study selection.

(1988-2015). The majority of studies were from the USA (55 studies); the remainder were from Europe (33 studies), Canada (11 studies) and Australia (1 study). Interrater agreement for study screening was adequate $(98 \%, \kappa=0.41$, adjusted $\kappa=0.97)$. Forest plots for the studies included in the quantitative analysis are shown in Figs 2 and 3. Online Table DS1 presents an overview of the social support and depression measures used in the research.

\section{Children and adolescents}

The search identified 31 studies that assessed social support and protection from depression in children and adolescents, ranging in age from 8 to 20 years (see online Tables DS2 and DS3 for study characteristics and details of ratings respectively). A significant association between at least one aspect of social support and protection from depression was reported in $84 \%$ of studies (Table 1). Evidence suggested a strong association between social support and absence of depression (pooled $\mathrm{OR}=0.20,95 \%$ CI 0.19 to 0.20 ). Odds ratios ranged from 0.12 to 0.82 (see Fig. 2). Findings from studies that used continuous depression scores were less consistent (pooled beta coefficient $-0.06,95 \%$ CI -0.09 to -0.03 ). Beta coefficients ranged from -1.73 to 0.06 (see Fig. 3). Estimates were generally stronger and more likely to be significant in cross-sectional studies than in cohort studies, and in low- or moderate-quality studies than in high-quality studies (Table 1). Removing low-quality studies from the meta-analysis did not affect pooled estimates. In studies that reported genderspecific estimates a significant association was found consistently for girls (all of 11 studies found a significant association) but not for boys ( 8 of 11 studies). Parents, teachers and family were sources of support most consistently found to be protective against depression in children and adolescents $(80 \%, 86 \%$ and 


\begin{tabular}{|c|c|c|c|c|}
\hline & $\begin{array}{l}\text { Children } \\
\text { and adolescents }{ }^{\mathrm{a}}\end{array}$ & $\begin{array}{l}\text { Adults and general } \\
\text { population }^{\mathrm{a}}\end{array}$ & Older adults ${ }^{a}$ & All $^{\mathrm{a}}$ \\
\hline Overall & $84 \%(26 / 31)$ & $92 \%(33 / 36)$ & $94 \%(31 / 33)$ & $90 \%(90 / 100)$ \\
\hline \multicolumn{5}{|l|}{ Study design } \\
\hline Cross-sectional & $83 \%(15 / 18)$ & $89 \%(25 / 28)$ & $100 \%(23 / 23)$ & $91 \%(63 / 69)$ \\
\hline Cohort & $77 \%(10 / 13)$ & $100 \%(8 / 8)$ & $80 \%(8 / 10)$ & $84 \%(26 / 31)$ \\
\hline \multicolumn{5}{|l|}{ Study quality } \\
\hline Low & $100 \%(5 / 5)$ & $100 \%(4 / 4)$ & $0 \%(0 / 1)$ & $90 \%(9 / 10)$ \\
\hline Moderate & $80 \%(16 / 20)$ & $89 \%(24 / 27)$ & $96 \%(25 / 26)$ & $89 \%(65 / 73)$ \\
\hline High & $67 \%(4 / 6)$ & $100 \%(5 / 5)$ & $100 \%(6 / 6)$ & $88 \%(15 / 17)$ \\
\hline \multicolumn{5}{|l|}{ Gender } \\
\hline Women & $100 \%(11 / 11)$ & $86 \%(6 / 7)$ & $71 \%(5 / 7)$ & $88 \%(22 / 25)$ \\
\hline Men & $73 \%(8 / 11)$ & $80 \%(4 / 5)$ & $100 \%(6 / 6)$ & $82 \%(18 / 22)$ \\
\hline \multicolumn{5}{|l|}{ Aspect of social support } \\
\hline General perceived support & $33 \%(1 / 3)$ & $78 \%(14 / 18)$ & $83 \%(15 / 18)$ & $77 \%(30 / 39)$ \\
\hline \multicolumn{5}{|l|}{ Source of social support } \\
\hline Support from spouse & & $100 \%(9 / 9)$ & $100 \%(6 / 6)$ & $100 \%(15 / 15)$ \\
\hline Support from family & $86 \%(6 / 7)$ & $88 \%(7 / 8)$ & $36 \%(4 / 11)$ & $65 \%(17 / 26)$ \\
\hline Support from parents & $80 \%(12 / 15)$ & & & $80 \%(12 / 15)$ \\
\hline Support from children & & $67 \%(2 / 3)$ & $50 \%(3 / 6)$ & $56 \%(5 / 9)$ \\
\hline Support from friends & $56 \%(9 / 16)$ & $73 \%(8 / 11)$ & $71 \%(5 / 7)$ & $65 \%(22 / 34)$ \\
\hline Support from teacher & $86 \%(6 / 7)$ & & & $86 \%(6 / 7)$ \\
\hline Support from work & & $100 \%(1 / 1)$ & & $100 \%(1 / 1)$ \\
\hline \multicolumn{5}{|l|}{ Type of social support } \\
\hline Emotional support & & $86 \%(6 / 7)$ & $50 \%(2 / 4)$ & $73 \%(8 / 11)$ \\
\hline Instrumental support & & $67 \%(6 / 9)$ & $50 \%(2 / 4)$ & $62 \%(8 / 13)$ \\
\hline Informational support & & $100 \%(1 / 1)$ & & $100 \%(1 / 1)$ \\
\hline
\end{tabular}

$86 \%$ of studies reported a significant association for each type of support respectively), whereas findings were less consistent for support from friends and general perceived support (56\% and $33 \%$ of studies with significant findings respectively) (Table 1). In additional analysis we found that parental and family support was particularly important for girls (80\% of studies reported a significant association) but less so for boys (40\% of studies reported a significant association). No study on type of social support (emotional, instrumental, informational) in youth was found in this review. Measurement tools to assess social support varied broadly, with each of the 31 studies using a unique scale, of which less than half were validated (online Table DS1).

\section{Adults}

A total of 36 studies measured the association between social support and protection from depression in samples of adults (see online Tables DS4 and DS5 for study characteristics and details of ratings respectively). Ages ranged from 18 years and older, except for one study which included a general population sample of Germans aged 16 years and older, ${ }^{48}$ and another of Canadians aged 12 years and older. ${ }^{78}$ A majority of studies (89\%) reported a significant association between social support and protection from depression among adults. In studies that used binary depression outcomes (pooled $\mathrm{OR}=0.74,95 \% \mathrm{CI} 0.72$ to 0.76 ) odds ratios ranged between 0.23 and 1.07 (see Fig. 2). In studies that used continuous depression scores (pooled beta coefficient $-0.01,95 \%$ CI -0.02 to -0.01 ) beta coefficients ranged between -4.90 and 0.21 (see Fig. 3). In studies that conducted gender-specific analyses findings were similarly significant in samples of women $(86 \%)$ and men $(80 \%)$ (Table 1 ). The numbers of statistically significant findings were also similar in cross-sectional and cohort studies and across studies of low, moderate and high quality. Excluding low-quality studies from the meta-analysis did not substantially change pooled estimates.

The source of social support most consistently associated with protection from depression in adults was spousal support (100\% of studies reported a significant association) followed by support from family ( $88 \%$ of studies), friends ( $73 \%$ of studies) and children (67\% of studies). The type of social support most consistently associated with protection from depression in adults was emotional support (75\% of studies reported a significant association) followed by instrumental support (67\% of studies); informational support was examined in one study and was not found to be significantly associated with protection from depression (Table 1). Each study used a unique instrument to measure social support, except for the Interpersonal Support Evaluation List, which was used in three studies (online Table DS1). About a third of studies used a previously validated social support scale.

\section{Older adults}

The search identified 33 studies examining social support and protection from depression specifically in samples of adults aged 50 years and older (see online Tables DS6 and DS7 for study characteristics and details of ratings respectively). Over $90 \%$ of studies found a significant association between some aspect of social support and protection from depression in older adults. In studies that modelled binary depression outcomes (pooled $\mathrm{OR}=0.56,95 \%$ CI 0.55 to 0.57 ), odds ratios ranged from 0.06 to 1.49 (see Fig. 2). In studies modelling continuous depression outcomes (pooled beta coefficient $-0.11,95 \%$ CI -0.13 to -0.08 ), beta coefficients ranged from -4.23 to 0.66 (see Fig. 3 ). Results were consistently significant in men (all of 6 studies 


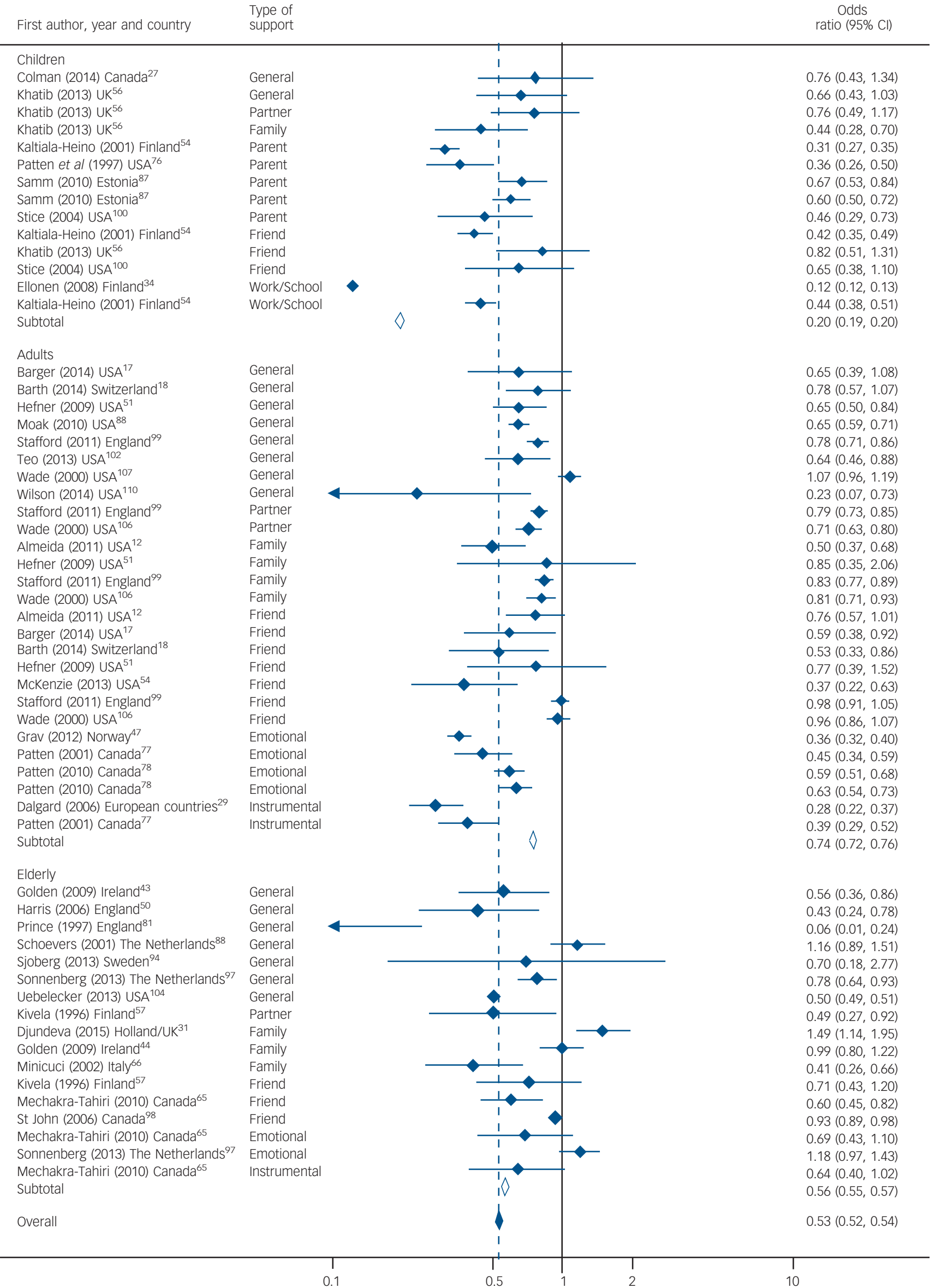

Fig. 2 Forest plot of studies using a dichotomous depression outcome, categorised by life period. 


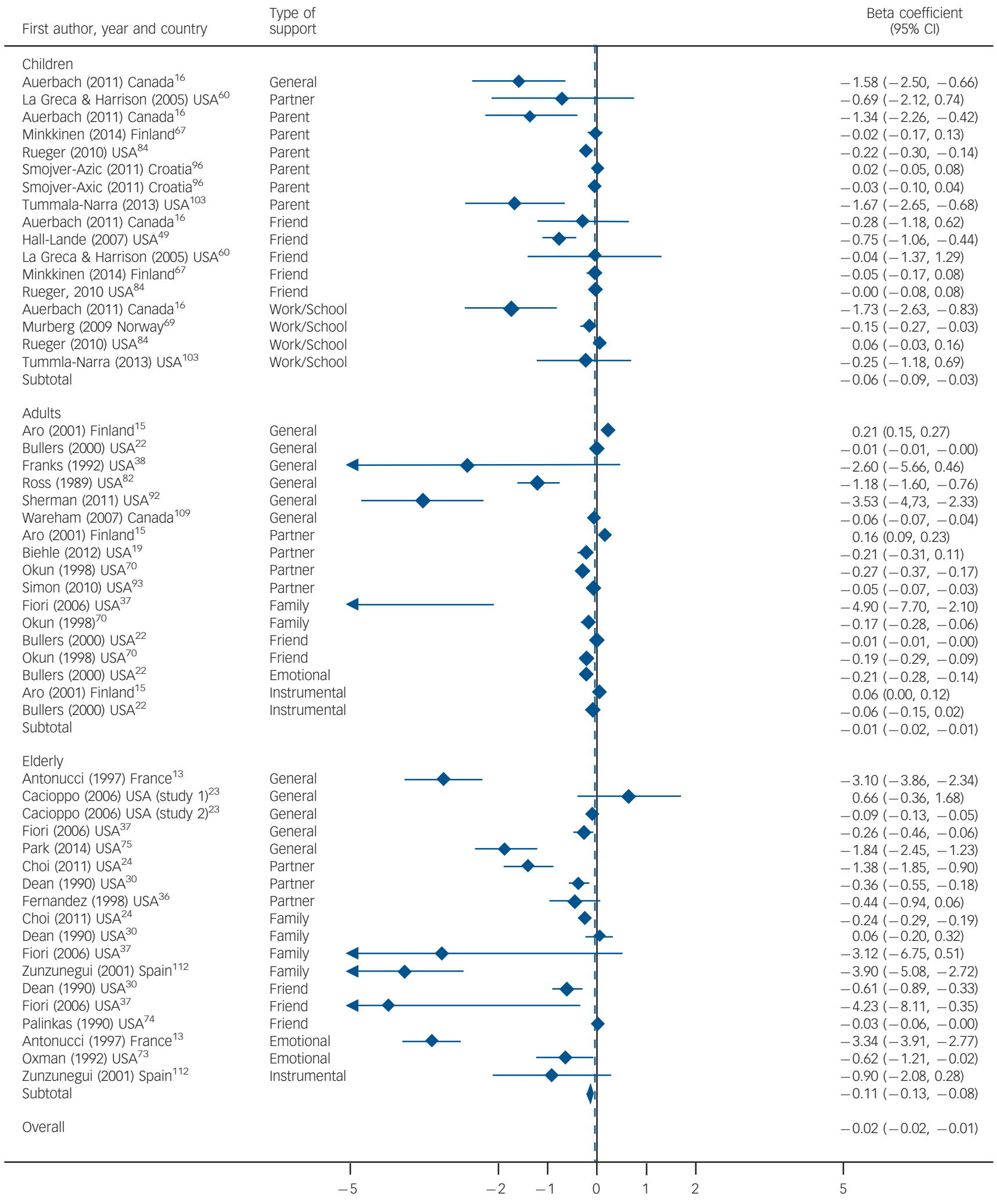

Fig. 3 Forest plot of studies using a continuous depression outcome, categorised by life period.

found a significant association) but less so in women (5 of 7 studies). Cross-sectional studies found significant results more often than cohort studies (Table 1). Study quality did not affect consistency of significant results and removing low-quality studies did not affect pooled estimates. As in the adult studies, spouses were the source of social support most consistently associated with protection from depression (all studies), followed by support from friends (83\% of studies) (Table 1). Evidence for support from children and family was less consistent (50\% and $36 \%$ of studies respectively reported a significant association). Evidence for emotional support and instrumental support relating to protection from depression was supported in half the studies. Each study 
used a unique social support measurement tool, of which only about a third were validated (online supplement DS1).

\section{Discussion}

This study provides the most comprehensive systematic literature review to date on the association between social support and protection from depression. Further, it is the first to contrast evidence for this association across life periods and provide meta-analytic estimates of association within each of these periods. We identified 100 studies that reported on aspects of social support and protection from depression across all ages. Evidence is overall highly consistent and supports the notion that social support is an important protective factor against depression. However, the sources of social support that were most protective of depression varied across the life periods. Parental support was most consistently associated with protection from depression in children and adolescents, whereas spousal support was most salient for adults and older adults. Furthermore, the review identified large variations in the operationalisation and measurement of social support. Over ten different aspects of social support were investigated in the literature, measured with close to a hundred different measurement tools. Finally, an important limitation of this body of evidence is that most studies were cross-sectional, thus precluding inference of the direction of association between social support and protection from depression. This caveat is particularly salient for studies of children and adolescents, in which the cross-sectional estimates were larger and more significant than those of the cohort studies, suggesting that reverse causality (i.e. a perception of greater support among the least depressed) might be inflating estimates in the former set of studies.

\section{Children and adolescents}

Support from parents and family is most consistently related to a youth's protection from depression, more than any other source. Children and adolescents rely on their parents to meet their basic needs, such as emotional assistance and material resources. Parental support has been shown to affect a child's mental health development, ${ }^{113,114}$ which in turn may contribute to protection from depression. In this review, parental support was particularly important for girls. This effect may be attributable to genderspecific parent-child dyads. ${ }^{115}$ Among the three studies that investigated maternal and paternal support independently from each other, all studies reported maternal support to be a significant protective factor from depression in girls, but only one study reported this for boys, and only in the context of single-mother households. ${ }^{76}$ These findings are supported by others that suggest maternal support is a particularly important component of development and mental well-being in girls. ${ }^{116}$ Conversely, paternal support was associated with protection from depression in two-thirds of studies, equally for girls and boys. Others have demonstrated the importance of paternal involvement on child behaviours and outcomes. ${ }^{116}$ Interestingly - and perhaps contrary to popular belief that views peer support as a substitute for parental support (particularly in adolescence) - social support from friends was not consistently associated with protection from depression in samples of children and adolescents. Peer support has been shown to be important in the psychological development of children. However, friendships during adolescence are more transitory and may be less reliable sources of support than parents and family. ${ }^{117}$ Furthermore, cross-sectional studies do not permit assessment of the possibility that depression might also adversely affect the capacity to develop friendships in these crucial formative years. $^{118}$

\section{Adults}

In samples of adults evidence is strongest for spousal support as a protective factor against depression. Evidence also suggests that both social support (e.g. empathy) and social strain (e.g. criticism) from a spouse are significantly related to depressive symptoms in adults, although in opposite directions, ${ }^{70,93,119}$ and both giving and receiving support from a spouse is associated with lower levels of depressive symptoms. ${ }^{19}$ Evidence was also highly consistent for family support as a protective factor against depression in adults, but was mixed for friend support. Adulthood is a time when family responsibilities are greatest and a main source of stress. In this context, spousal and family support to assist with parental obligations may be particularly important to mental health. ${ }^{120}$ In addition, as the composition of networks tends to shift across adulthood to include more family members than friends, family may therefore represent a more available source of support. ${ }^{121}$

Emotional support is a highly consistent protective factor against depression in adults compared with instrumental support. Emotional support, such as having someone to confide in, attempts to directly reduce the negative emotions associated with a distressing situation, ${ }^{122}$ whereas instrumental support such as having someone to help with chores or in case of a crisis may benefit mental health more indirectly, by providing respite from chronic and acute stress. Alternatively, given the dearth of longitudinal studies, these results could be indicative of reverse causality, whereby emotional support is mostly activated in situations of greater need, and thus could be spuriously found to be associated with greater distress and depression. ${ }^{123}$ Emotional support could also be more easily provided, particularly when the provider and recipient are geographically distant, as instrumental support often requires a physical presence.

\section{Older adults}

In elderly samples spousal support is a consistent protective factor against depression, particularly in men. Results from two longitudinal studies suggest that having a poor relationship with a spouse, ${ }^{54}$ or having no partner in the household, ${ }^{97}$ were associated with depression in older men. This evidence supports established evidence that spousal support may be particularly important for the health of men. ${ }^{124}$ Cross-sectional evidence, however, shows spousal support to be significant for both genders. ${ }^{24}$ Unlike earlier life periods, evidence for a protective effect of family support was weak among older adults. Only a third of studies that examined family support reported a significant association. The role of family and relatives may change with older age, as relatives are also ageing (or may die) and may become less able to offer support. The type of social support that older individuals need from their family for mental health could also be different from that for younger adults. For example, Minicuci et al found that poor financial support from family members was associated with depression in older men, but poor emotional support was not. ${ }^{66}$ Further research on the type of social support that is relevant to prevent depression in older age is needed.

Across the different life periods support from friends was most consistently associated with protection from depression in older adults. Support from friends could be an adjunct to support from spouse and family. It is possible that friendship and companionship become more important with older age as spouses and family become less available due to illness and death. ${ }^{125}$ This pattern of evidence is supported by studies that 
stratified their sample by age group. Fiori et al found that positive support from friends was significantly associated with less depressive symptoms in older adults (age 60+ years), but not in younger adults (35-59 years old). ${ }^{37}$ Similarly, Okun \& Keith found that support from friends and/or relatives (other than spouse or children) was significantly and strongly related to less depressive symptoms in older adults (60-92 years old) but not in younger adults (28-59 years old). ${ }^{70}$

Children could be an additional source of support against depression in older adults, yet evidence for this is weak and mixed. Only half of the studies investigating support from children found a significant association. However, support from children was measured in a variety of ways, such as getting help from children, receiving expressive or emotional support, or number of children seen weekly. The exact role of social support from children for their older parents is therefore not clear. Children may provide important instrumental support or companionship to their parents, but evidence for these types of support is absent. In addition, reverse causality may apply here as well, as children may come to be involved in providing support with increasing loss of autonomy, which is typically associated with increased risk of depression. $^{126}$

\section{Limitations of the studies}

Social support measurement

An important finding of this review is the large number of instruments researchers used to measure and operationalise social support, which limits the replication of findings. General perceived social support (e.g. 'Do you have someone you can really count on to help you out in a crisis situation?') was the most common measure of social support. Yet this measure does not fully capture the range of social support available to individuals, which may vary between individuals and over the life course. Additionally, perceived general social support may not be a reliable measure in children, who may not have the life experience or self-reflection to make a general assessment of their personal level of social support. Less than half of studies in the literature used a validated social support instrument. Scales that have not been validated may not accurately measure social support or might capture elements of life beyond social support, such as physical health, personality traits (e.g. extroversion) and living arrangement (e.g. living alone). ${ }^{127,128}$ The concept of time in social support measurement has also been largely ignored up to now. Except for one study, ${ }^{30}$ none of the scales used a time frame when assessing social support. Consequently, perception of social support may refer to various time periods depending on the individual, and may include future expectation of support. Social support may further change over time in response to life events, yet the majority of longitudinal studies examined social support at a single point in time. There may be a reciprocal relationship between depressive symptoms and social support, as social withdrawal may drive away social ties. There is also a dearth of evidence on the protective effects of social support against depression across the life course. In the only life course study to date, authors found that parental support during childhood decreased depressive symptoms in adulthood. ${ }^{90}$ Further high-quality longitudinal studies are needed to confirm these results.

\section{Depression measurement}

Depressive symptoms were generally measured from self-report screening depression scales. Although the majority of scales are validated instruments, they are screening tools and not clinical interviews, and may therefore overestimate the presence of mood problems. The time frame of reference for depressive symptoms ranged from current symptoms to lifetime depression. The strength of associations tended to be greater in studies that measured current or past-week depressive symptoms than in studies that used longer time frames. Current depressive symptoms might be more strongly associated with perceived social support because being depressed may affect the perception of social support. A shorter time frame might also rely less on recall and provide a more reliable assessment of depressive problems.

\section{Limitations of our review}

As with any review, publication bias is possible. Publishers and authors tend to favour the publication of significant findings over non-significant ones. We were only able to review papers in English, French and Finnish, potentially missing some studies. Nevertheless, we only found English studies to fit our criteria. We included only studies from Western countries; results may therefore have limited generalisability to other geographical areas, particularly low-income countries and/or other cultural contexts. Future research focusing on other cultures and countries is recommended. We restricted our search to samples from the general population. The association between social support and protection from depression may differ in vulnerable subgroups.

\section{Strengths of the review}

We used a rigorous methodology to search and assess the published research on the inverse association between social support and depression. Two reviewers independently examined the evidence. We favoured an in-depth analysis of the literature to explain current findings and trends, complemented by a meta-analysis to summarise findings. We carefully sought to assess the association between social support and protection from depression overall and across life periods, a topic that has not been specifically reviewed in the literature.

\section{Future research}

Our review provides consistent evidence of an association between social support and protection from depression in samples of the general population across all ages. Sources of support tended to vary in importance across life periods, with parental support being most consistently associated with protection from depression in children and adolescents, and spousal support in adults and older adults. Significant heterogeneity in social support measurement is a key finding of this review. Future studies using validated social support scales are recommended. As the contrast in magnitude and significance of effects between cohort and cross-sectional studies suggests the presence of reverse causation in these associations, research on the temporal dynamics of social support and protection from depression, particularly over the life course, is also strongly encouraged.

\footnotetext{
Geneviève Gariépy, PhD, Institute for Health and Social Policy, McGill University, Montreal, Canada; Helena Honkaniemi, BSc, International Research Infrastructure on Social Inequalities in Health, McGill University, Montreal, Canada; Amélie Quesnel-Vallée, MSc, PhD, International Research Infrastructure on Social Inequalities in Health, Department of Epidemiology, Biostatistics and Occupational Health, and Department of Sociology, McGill University, Montreal, Quebec, Canada

Correspondence: Dr Amélie Quesnel-Vallée, International Research Infrastructure on Social Inequalities in Health, McGill University, Stephen Leacock Building, Room 713, 855 Sherbrooke Street West, Montreal, Quebec H3A 2T7, Canada. Email: amelie.quesnelvallee@mcgill.ca

First received 16 Jul 2014, final revision 29 Jan 2016, accepted 27 Feb 2016
} 


\section{Funding}

This work was supported by the Canadian Institutes of Health Research (Operating Grant MIN127270, PI: Quesnel-Vallée). G.G. was supported by funding from the Canadian Institutes of Health Research; A.Q.V. was supported by a salary award from Fonds de la Recherche en Santé du Québec and holds the Canada Research Chair on Policies and Health Inequalities.

\section{References}

1 Murray $\mathrm{CJ}$, Vos $\mathrm{T}$, Lozano $\mathrm{R}$, Naghavi $\mathrm{M}$, Flaxman $\mathrm{AD}$, Michaud $\mathrm{C}$, et al. Disability-adjusted life years (DALYS) for 291 diseases and injuries in 21 regions, 1990-2010: a systematic analysis for the Global Burden of Disease Study 2010. Lancet 2012; 380: 2197-223.

2 Patel V, Goodman A. Researching protective and promotive factors in mental health. Int J Epidemiol 2007; 36: 703-7.

3 House JS, Umberson D, Landis KR. Structures and processes of social support. Annu Rev Sociol 1988; 14: 293-318.

4 O'Connell RA, Mayo JA. The role of social factors in affective disorders: a review. Hosp Community Psychiatry 1988; 39: 842-51.

5 Avison WR. Social networks as risk and protective factors for onset and recurrence of mental disorders. Curr Opin Psychiatry 1996; 9: 149-52.

6 Kawachi I, Berkman LF. Social ties and mental health. J Urban Health 2001; 78: 458-67.

7 Kurlowicz LH. Social factors and depression in late life. Arch Psychiatr Nurs 1993; 7: 30-6.

8 Bruce ML. Psychosocial risk factors for depressive disorders in late life. Bio Psychiatry 2002; 52: 175-84.

9 De Silva MJ, Huttly SR, Harpham T, Kenward MG. Social capital and mental health: a comparative analysis of four low income countries. Soc Sci Med 2007; 64: 5-20.

10 Byrt T, Bishop J, Carlin JB. Bias, prevalence and kappa. J Clin Epidemiol 1993; 46: 423-9.

11 Wells GA, Shea B, O'Connell D, Peterson J, Welch V, Losos M, et al. The Newcastle-Ottawa Scale (NOS) for assessing the quality of nonrandomised studies in meta-analyses. Ottawa Health Research Institute (http://www.ohri.ca/programs/clinical_epidemiology/oxford.htm).

12 Almeida J, Subramanian S, Kawachi I, Molnar B. Is blood thicker than water? Social support, depression and the modifying role of ethnicity/nativity status. J Epidemiol Community Health 2011; 65: 51-6.

13 Antonucci TC, Fuhrer R, Dartigues JF. Social relations and depressive symptomatology in a sample of community-dwelling French older adults. Psychol Aging 1997; 12: 189-95.

14 Antonucci TC, Lansford JE, Akiyama $\mathrm{H}$. Impact of positive and negative aspects of marital relationships and friendships on well-being of older adults. Appl Dev Sci 2001; 5: 68-75.

15 Aro AR, Nyberg N, Absetz P, Henriksson M, Lonnqvist J. Depressive symptoms in middle-aged women are more strongly associated with physical health and social support than with socioeconomic factors. Nord J Psychiatry 2001; 55: 191-8.

16 Auerbach RP, Bigda-Peyton JS, Eberhart NK, Webb CA, Ho MHR. Conceptualizing the prospective relationship between social support, stress, and depressive symptoms among adolescents. J Abnorm Child Psychol 2011 39: 475-87.

17 Barger SD, Messerli-Buergy N, Barth J. Social relationship correlates of major depressive disorder and depressive symptoms in Switzerland: nationally representative cross sectional study. BMC Public Health 2014; 14.

18 Barth J, Hofmann K, Schori D. Depression in early adulthood: prevalence and psychosocial correlates among young Swiss men. Swiss Med Wkly 2014; 144: W13945.

19 Biehle SN, Mickelson KD. Provision and receipt of emotional spousal support The impact of visibility on well-being. Couple Fam Psychol 2012; 1: 244-51.

20 Bisconti TL, Bergeman C. Perceived social control as a mediator of the relationships among social support, psychological well-being, and perceived health. Gerontologist 1999; 39: 94-103.

21 Bosacki S, Dane A, Marini Z. Peer relationships and internalizing problems in adolescents: mediating role of self-esteem. Emot Behav Diffic 2007; 12: 261-82.

22 Bullers S. The mediating role of perceived control in the relationship between social ties and depressive symptoms. Women Health 2000; 31: 97-116.

23 Cacioppo JT, Hughes ME, Waite LJ, Hawkley LC, Thisted RA. Loneliness as a specific risk factor for depressive symptoms: cross-sectional and longitudinal analyses. Psychol Aging 2006; 21: 140-51.
24 Choi NG, Ha JH. Relationship between spouse/partner support and depressive symptoms in older adults: gender difference. Aging Ment Health 2011; 15: 307-17.

25 Colarossi LG, Eccles JS. Differential effects of support providers on adolescents' mental health. Soc Work Res 2003; 27: 19-30.

26 Coleman PG, Carare RO, Petrov I, Forbes E, Saigal A, Spreadbury JH, et al. Spiritual belief, social support, physical functioning and depression among older people in Bulgaria and Romania. Aging Ment Health 2011; 15: 327-33.

27 Colman I, Zeng Y, McMartin SE, Naicker K, Ataullahjan A, Weeks M, et al. Protective factors against depression during the transition from adolescence to adulthood: findings from a national Canadian cohort. Prevent Med 2014; 65: 28-32.

28 Cornwell B. The dynamic properties of social support: decay, growth, and staticity, and their effects on adolescent depression. Soc Forces 2003; 81: 953-78.

29 Dalgard OS, Dowrick C, Lehtinen V, Vazquez-Barquero JL, Casey P, Wilkinson $G$, et al. Negative life events, social support and gender difference in depression: a multinational community survey with data from the ODIN study. Soc Psychiatry Psychiatr Epidemiol 2006; 41: 444-51.

30 Dean A, Kolody B, Wood P. Effects of social support from various sources on depression in elderly persons. J Health Soc Behav 1990; 31: 148-61.

31 Djundeva M, Mills $M$, Wittek R, Steverink N. Receiving instrumental support in late parent-child relationships and parental depression. J Gerontol B Psychol Sci Soc Sci 2015; 70: 981-94.

32 Donnelly M. Factors associated with depressed mood among adolescents in Northern Ireland. J Community Appl Soc Psychol 1999; 9: 47-59.

33 Elliot M. Gender differences in causes of depression. Women Health 2001; 33: $163-77$.

34 Ellonen N, Kaariainen J, Autio V. Adolescent depression and school social support: a multilevel analysis of a Finnish sample. J Community Psychol 2008; 36: 552-67.

35 Feldman S, Rubenstein JL, Rubin C. Depressive affect and restraint in early adolescents: relationships with family structure, family process and friendship support. J Early Adolesc 1988; 8: 279-96.

36 Fernandez ME, Mutran EJ, Reitzes DC. Moderating the effects of stress on depressive symptoms. Res Aging 1998; 20: 163-82.

37 Fiori KL, Mcllvane JM, Brown EE, Antonucci TC. Social relations and depressive symptomatology: self-efficacy as a mediator. Aging Ment Health 2006; 10: 227-39.

38 Franks $\mathrm{P}$, Shields C, Campbell T, McDaniel S, Harp J, Botelho RJ. Association of social relationships with depressive symptoms: testing an alternative to social support. J Fam Psychol 1992; 6: 49-59.

39 Galambos NL, Leadbeater BJ, Barker ET. Gender differences in and risk factors for depression in adolescence: a 4-year longitudinal study. Int J Behav Dev 2004; 28: 16-25.

40 Galand B, Hospel V. Peer victimization and school disaffection: exploring the moderation effect of social support and the mediation effect of depression. Br J Educ Psychol 2013; 83: 569-90.

41 Ge X, Natsuaki MN, Neiderhiser JM, Reiss D. The longitudinal effects of stressful life events on adolescent depression are buffered by parent-child closeness. Devel Psychopathol 2009; 21: 621-35.

42 Glaesmer H, Riedel-Heller S, Braehler E, Spangenberg L, Luppa M. Age- and gender-specific prevalence and risk factors for depressive symptoms in the elderly: a population-based study. Int Psychogeriatr 2011; 23: 1294-300.

43 Golden J, Conroy RM, I, Denihan A, Greene E, Kirby M, Lawlor BA. Loneliness, social support networks, mood and wellbeing in community-dwelling elderly. Int J Geriatr Psychiatry 2009; 24: 694-700.

44 Golden J, Conroy RM, Lawlor BA. Social support network structure in older people: underlying dimensions and association with psychological and physical health. Psychol Health Med 2009; 14: 280-90.

45 Golding JM. Role occupancy and role-specific stress and social support as predictors of depression. Basic Appl Soc Psychol 1989; 10: 173-195.

46 Grant I, Patterson TL, Yager J. Social supports in relation to physical health and symptoms of depression in the elderly. Am J Psychiatry 1988; 145: 1254-8.

47 Grav S, Hellzen O, Romild U, Stordal E. Association between social support and depression in the general population: the HUNT study, a cross-sectional survey. J Clin Nurs 2012; 21: 111-20.

48 Grumer S, Pinquart M. Perceived changes in personal circumstances related to social change: associations with psychosocial resources and depressive symptoms. Eur Psychol 2011; 16: 68-78.

49 Hall-Lande JA, Eisenberg ME, Christenson SL, Neumark-Sztainer D. Social isolation, psychological health, and protective factors in adolescence. Adolescence 2007; 42: 265-86. 
50 Harris T, Cook DG, Victor C, DeWilde S, Beighton C. Onset and persistence of depression in older people - results from a 2-year community follow-up study. Age Ageing 2006; 35: 25-32.

51 Hefner J, Eisenberg D. Social support and mental health among college students. Am J Orthopsychiatry 2009; 79: 491-9.

52 Heponiemi T, Elovainio M, Kivimaki M, Pulkki L, Puttonen S, Keltikangas-Jarvinen $L$. The longitudinal effects of social support and hostility on depressive tendencies. Soc Sci Med 2006; 63: 1374-82.

53 Hussong AM. Perceived peer context and adolescent adjustment. J Res Adolesc 2000; 10: 391-415.

54 Kaltiala-Heino R, Rimpela M, Rantanen P, Laippala P. Adolescent depression: the role of discontinuities in life course and social support. J Affect Disord 2001; 64: 155-66.

55 Kendler KS, Myers J, Prescott CA. Sex differences in the relationship between social support and risk for major depression: a longitudinal study of oppositesex twin pairs. Am J Psychiatry 2005; 162: 250-6.

56 Khatib Y, Bhui K, Stansfeld SA. Does social support protect against depression and psychological distress? Findings from the RELACHS study of East London adolescents. J Adolesc 2013; 36: 393-402.

57 Kivela SL, Kongas-Saviaro P, Laippala P, Pahkala K, Kesti E. Social and psychosocial factors predicting depression in old age: a longitudinal study. Int Psychogeriatr 1996; 8: 635-44.

58 Klima T, Repetti RL. Children's peer relations and their psychological adjustment: differences between close friendships and the larger peer group. Merrill Palmer Q 2008; 54: 151-78.

59 Krause N, Liang J, Yatomi N. Satisfaction with social support and depressive symptoms: a panel analysis. Psychol Aging 1989; 4: 88-97.

60 La Greca AM, Harrison HM. Adolescent peer relations, friendships, and romantic relationships: do they predict social anxiety and depression? J Clin Child Adolesc Psychol 2005; 34: 49-61.

61 Lewis GJ, Bates TC, Posthuma D, Polderman TJC. Core dimensions of personality broadly account for the link from perceived social support to symptoms of depression and anxiety. J Pers 2014; 82: 329-39.

62 Lin N, Ye X, Ensel WM. Social support and depressed mood: a structural analysis. J Health Soc Behav 1999; 40: 344-59.

63 Marcotte G, Marcotte D, Bouffard T. The influence of familial support and dysfunctional attitudes on depression and delinquency in an adolescent population. Eur J Psychol Educ 2002; 17: 363-76.

64 McKenzie LE, Polur RN, Wesley C, Allen JD, McKeown RE, Zhang J. Social contacts and depression in middle and advanced adulthood: findings from US national survey, 2005-2008. Int J Soc Psychiatry 2013; 59: 627-35.

65 Mechakra-Tahiri SD, Zunzunegui MV, Preville M, Dube M. Gender, social relationships and depressive disorders in adults aged 65 and over in Quebec. Chron Dis Can 2010; 30: 56-65.

66 Minicuci N, Maggi S, Pavan M, Enzi G, Crepaldi G. Prevalence rate and correlates of depressive symptoms in older individuals: the Veneto study. J Gerontol A Biol Sci Med Sci 2002; 57: M155-61.

67 Minkkinen J. Associations between school-related factors and depressive symptoms among children: a comparative study, Finland and Norway. School Psychol Int 2014; 35: 463-74.

68 Moak ZB, Agrawal A. The association between perceived interpersonal social support and physical and mental health: results from the national epidemiological survey on alcohol and related conditions. J Publ Health 2010; 32: 191-201.

69 Murberg TA, Bru E. The relationships between negative life events, perceived support in the school environment and depressive symptoms among Norwegian senior high school students: a prospective study. Soc Psychol Educ 2009; 12: 361-70.

70 Okun MA, Keith VM. Effects of positive and negative social exchanges with various sources on depressive symptoms in younger and older adults. J Gerontol B Psychol Sci Soc Sci 1998; 53: P4-20.

71 Oldenburg CM, Kerns KA. Associations between peer relationships and depressive symptoms: testing moderator effects of gender and age. J Early Adolesc 1997; 17: 319-37.

72 Osborn DP, Fletcher AE, Smeeth L, Stirling S, Bulpitt J, Breeze E, et al. Factors associated with depression in a representative sample of 14217 people aged 75 and over in the United Kingdom: results from the MRC trial of assessment and management of older people in the community. Int J Geriatr Psychiatry 2003; 18: 623-30.

73 Oxman TE, Berkman LF, Kasl S, Freeman DH, Barrett J. Social support and depressive symptoms in the elderly. Am J Epidemiol 1992; 135: 356-68.

74 Palinkas LA, Wingard DL, Barrett-Connor E. The biocultural context of socia networks and depression among the elderly. Soc Sci Med 1990; 30: 441-7.
75 Park NS, Jang Y, Lee BS, Ko JE, Chiriboga A. The impact of social resources on depressive symptoms in racially and ethnically diverse older adults: variations by groups with differing health risks. Res Aging 2014; 36: 322-42.

76 Patten CA, Gillin J, Farkas AJ, Gilpin EA, Berry CC, Pierce JP. Depressive symptoms in California adolescents: family structure and parental support $J$ Adolesc Health 1997; 20: 271-8.

77 Patten SB. Descriptive epidemiology of a depressive syndrome in a western Canadian community population. Can J Public Health 2001; 92: 392-5.

78 Patten SB, Williams JV, Lavorato DH, Bulloch AG. Reciprocal effects of social support in major depression epidemiology. Clin Pract Epidemiol Ment Health 2010; 6: 126-31.

79 Peirce RS, Frone MR, Russell M, Cooper M, Mudar P. A longitudinal model of social contact, social support, depression, and alcohol use. Health Psychol 2000; 19: 28-38.

80 Piko BF, Kovacs E, Fitzpatrick KM. What makes a difference? Understanding the role of protective factors in Hungarian adolescents' depressive symptomatology. Eur Child Adolesc Psychiatry 2009; 18: 617-24.

81 Prince M, Harwood R, Blizard R, Thomas A. Social support deficits, loneliness and life events as risk factors for depression in old age. The Gospel Oak Project VI. Psychol Med 1997; 27: 323-32.

82 Ross CE, Mirowsky J. Explaining the social patterns of depression: control and problem solving: or support and talking? J Health Soc Behav 1989; 30: 206-19.

83 Rubin C, Rubenstein JL, Stechler G, Heeren T, Halton A, Housman D, et al. Depressive affect in normal adolescents: relationship to life stress, family, and friends. Am J Orthopsychiatry 1992; 62: 430-41.

84 Rueger SY, Malecki CK, Demaray MK. Relationship between multiple sources of perceived social support and psychological and academic adjustment in early adolescence: comparisons across gender. J Youth Adolesc 2010; 39: 47-61.

85 Ruiz SA, Silverstein M. Relationships with grandparents and the emotional well-being of late adolescent and young adult grandchildren. J Soc Issues 2007; 63: 793-808.

86 Russell DW, Cutrona CE. Social support, stress, and depressive symptoms among the elderly: test of a process model. Psychol Aging 1991; 6: 190-201.

87 Samm A, Tooding LM, Sisask M, Kolves K, Aasvee K, Varnik A. Suicidal thoughts and depressive feelings amongst Estonian schoolchildren: effect of family relationship and family structure. Eur Child Adolesc Psychiatry 2010; 19: 457-68.

88 Schoevers RA, Beekman ATF, Deeg DJH, Geerlings MI, Jonker C, Van Tilburg W. Risk factors for depression in later life; results of a prospective community based study (AMSTEL). J Affect Disord 2000; 59: $127-37$

89 Segrin C. Age moderates the relationship between social support and psychosocial problems. Hum Commun Res 2003; 29: 317-42.

90 Shaw BA, Krause N, Chatters LM, Connell CM, Ingersoll-Dayton B. Emotional support from parents early in life, aging, and health. Psychol Aging 2004; 19 : 4-12.

91 Sheeber L, Hops H, Alpert A, Davis B, Andrews J. Family support and conflict: prospective relations to adolescent depression. J Abnorm Child Psychol 1997; 25: $333-44$

92 Sherman AM, Skrzypek A, Bell R, Tatum C, Paskett ED. The contribution of social support and social strain to depressive symptoms in African American, Native American, and European American women. J Soc Pers Relat 2011; 28: 1104-29.

93 Simon RW, Barrett AE. Nonmarital romantic relationships and mental health in early adulthood: does the association differ for women and men? J Health Soc Behav 2010; 51: 168-82.

94 Sjoberg L, Ostling S, Falk H, Sundh V, Waern M, Skoog I. Secular changes in the relation between social factors and depression: a study of two birth cohorts of Swedish septuagenarians followed for 5 years. $J$ Affect Disord 2013; 150: 245-52.

95 Slavin LA, Rainer KL. Gender differences in emotional support and depressive symptoms among adolescents: a prospective analysis. Am J Community Psychol 1990; 18: 407-21.

96 Smojver-Azic S, Bezinovic P. Sex differences in patterns of relations between family interactions and depressive symptoms in adolescents. Croat Med J 2011; 52: 469-77.

97 Sonnenberg C, Deeg D, van Tilburg T, Vink D, Stek M, Beekman A. Gender differences in the relation between depression and social support in later life. Int Psychogeriatr 2013; 25: 61-70.

98 St John PD, Blandford AA, Strain LA. Depressive symptoms among older adults in urban and rural areas. Int J Geriatr Psychiatry 2006; 21: 1175-80.

99 Stafford M, McMunn A, Zaninotto P, Nazroo J. Positive and negative exchanges in social relationships as predictors of depression: evidence from the English Longitudinal Study of Aging. J Aging Health 2011; 23: 607-28. 
100 Stice E, Ragan J, Randall P. Prospective relations between social support and depression: differential direction of effects for parent and peer support? J Abnorm Psychol 2004; 113: 155-9.

101 Stojanovic-Spehar S, Blazekovic-Milakovic S, Amerl-Sakic V, Kolic N, Supe S. Depression prevalence and estimation of psychosocial parameters within adult population in city of Zagreb. Psychiatr Danub 2009; 21: 497-507.

102 Teo AR, Choi H, Valenstein M. Social relationships and depression: ten-year follow-up from a nationally representative study. PLOS One 2013; 8: e62396.

103 Tummala-Narra P, Sathasivam-Rueckert N. Perceived support from adults, interactions with police, and adolescents' depressive symptomology: an examination of sex, race, and social class. J Adolesc 2013; 36: 209-19.

104 Uebelacker LA, Eaton CB, Weisberg R, Sands M, Williams C, Calhoun D, et al. Support and physical activity as moderators of life stress in predicting baseline depression and change in depression over time in the Women's Health Initiative. Soc Psychiatry Psychiatr Epidemiol 2013; 48: 1971-82.

105 Vanderhorst R, McLaren S. Social relationships as predictors of depression and suicidal ideation in older adults. Aging Ment Health 2005; 9: 517-25.

106 Wade TD, Kendler KS. The relationship between social support and major depression: cross-sectional, longitudinal, and genetic perspectives. J Nerv Mental Dis 2000; 188: 251-8.

107 Wade TJ, Cairney J. The effect of sociodemographics, social stressors, health status and psychosocial resources on the age-depression relationship. Can J Public Health 2000; 91: 307-12.

108 Wallace $\mathrm{K}$, Bisconti TL, Bergeman C. The mediational effect of hardiness on social support and optimal outcomes in later life. Basic Appl Soc Psychol 2001; 23: 267-79.

109 Wareham S, Fowler K, Pike A. Determinants of depression severity and duration in Canadian adults: the moderating effects of gender and socia support. J Appl Soc Psychol 2007; 37: 2951-79.

110 Wilson KT, Bohnert AE, Ambrose A, Davis DY, Jones DM, Magee MJ. Social, behavioral, and sleep characteristics associated with depression symptoms among undergraduate students at a women's college: a cross-sectional depression survey, 2012. BMC Womens Health 2014; 14.

111 Zunzunegui MV, Beland F, Otero A. Support from children, living arrangements, self-rated health and depressive symptoms of older people in Spain. Int J Epidemiol 2001; 30: 1090-9.

112 Peters JL, Sutton AJ, Jones DR, Abrams KR, Rushton L, Moreno SG. Assessing publication bias in meta-analyses in the presence of betweenstudy heterogeneity. J R Stat Soc Ser A Stat Soc 2010; 173: 575-91.

113 Boudreault-Bouchard AM, Dion J, Hains J, Vandermeerschen J, Laberge L, Perron M. Impact of parental emotional support and coercive control on adolescents' self-esteem and psychological distress: results of a four-year longitudinal study. J Adolesc 2013; 36: 695-704.
114 Holahan CJ, Valentiner DP, Moos RH. Parental support, coping strategies, and psychological adjustment: an integrative model with late adolescents. Youth Adolesc 1995; 24: 633-48.

115 Ex C, Janssens J. Maternal influences on daughters' gender role attitudes. Sex Roles 1998; 38: 171-86.

116 Carlson MJ. Family structure, father involvement, and adolescent behavioral outcomes. J Marriage Fam 2006; 68: 137-54.

117 Branje SJT, Frijns TOM, Finkenauer C, Engels R, Meeus WIM. You are my best friend: commitment and stability in adolescents' same-sex friendships. Pers Relatsh 2007; 14: 587-603.

118 Kennedy E, Spence SH, Hensley R. An examination of the relationship between childhood depression and social competence amongst primary school children. J Child Psychol Psychiatry 1989; 30: 561-73.

119 Stafford M, McMunn A, Zaninotto P, Nazroo J. Positive and negative exchanges in social relationships as predictors of depression: evidence from the English Longitudinal Study of Aging. J Aging Health 2011; 23: $607-28$

120 Pettit JW, Roberts RE, Lewinsohn PM, Seeley JR, Yaroslavsky I. Developmental relations between perceived social support and depressive symptoms through emerging adulthood: blood is thicker than water. J Fam Psychol 2011; 25: 127

121 Walen HR, Lachman ME. Social support and strain from partner, family, and friends: costs and benefits for men and women in adulthood. J Soc Pers Relat 2000; 17: 5-30

122 Thoits PA. Social support as coping assistance. J Consult Clin Psychol 1986; 54: $416-23$.

123 Seeman TE. Social ties and health: the benefits of social integration. Ann Epidemiol 1996; 6: 442-51.

124 Kiecolt-Glaser JK, Newton TL. Marriage and health: his and hers. Psychol Bull 2001; 127: 472-503.

125 Gupta V, Korte $\mathrm{C}$. The effects of a confidant and a peer group on the well-being of single elders. Int J Aging Hum Dev 1994; 39: 293-302.

126 Cole MG, Dendukuri N. Risk factors for depression among elderly community subjects: a systematic review and meta-analysis. Am J Psychiatry 2003; 160: 1147-56

127 Rascle N, Bruchon-Schweitzer M, Sarason IG. Short form of Sarason's social support questionnaire: French adaptation and validation. Psychol Rep 2005; 97: 195-202.

128 Holden L, Lee C, Hockey R, Ware RS, Dobson AJ Validation of the MOS Social Support Survey 6-item (MOS-SSS-6) measure with two large population-based samples of Australian women. Qual Life Res 2014; 23: 2849-53. 